To the Editors:

\title{
Knowledge of hypoglycaemia in patients with diabetes
}

Hypoglycaemia is a frequent complication in patients with diabetes leading to considerable morbidity and mortality (1). Occurrence of symptomatic hypoglycaemia was shown to be high in elderly Sri Lankan patients (2). The purpose of this study was to assess the knowledge of symptoms, prevention and treatment of hypoglycaemia in patients with diabetes and to seek a relationship between patients' knowledge of hypoglycaemic symptoms and their ability to recognise hypoglycaemic episodes.

A cross-sectional descriptive study was carried out at the diabetic clinic of Colombo South Teaching Hospital. Participants were randomly selected patients with diabetes attending the clinic. An interviewer administered questionnaire was used to assess knowledge of symptoms, treatment and prevention of hypoglycaemic episodes and to assess whether they were experiencing symptomatic hypoglycaemic episodes. Patients who were knowledgeable about at least the four most common hypoglycaemic symptoms - faintishness, palpitations, sweating and hunger - were considered knowledgeable about symptoms. Those who were experiencing at least four of eight commonly experienced hypoglycaemic symptoms - faintishnes, palpitations, sweating, hunger, visual disturbances, poor concentration, headache and fits (3) - were considered to be experiencing symptomatic hypoglycaemic episodes.

A total of 203 patients (age range 23 to 84 years) were studied (mean age 58.4, SD 10.4 years, mean duration of diabetes 6.8 , SD 6.9 years) of whom 150 (73.9\%) were females. $171(84.2 \%)$ patients were on one or more oral hypoglycaemic agent, while $9(4.4 \%)$ were on in-sulin alone. $8(3.9 \%)$ were using both insulin and oral hypoglycaemic agents. $15(7.4 \%)$ were on dietary control alone.

Only $42(20.7 \%)$ patients were knowledgeable about symptoms of hypoglycaemia. $117(57.6 \%)$ knew what to do to recover from a hypoglycaemic episode. Only $36(17.7 \%)$ were aware of the predisposing factors leading to hypoglycaemia. Males showed a better knowledge of symptoms of hypoglycaemia than females $(\mathrm{p}<0.05)$, and patients with better education showed better knowledge in managing hypoglycaemic episodes. Although the knowledge about hypoglycaemia was better among the patients who were educated by doctors the difference was not significant (table 1). $117(57.6 \%)$ patients have had symptomatic hypoglycaemic episodes but only $71(60.7 \%)$ of them admitted that they were experiencing hypoglycaemic episodes. Patients who had knowledge about symptoms were able to recognise hypoglycaemic episodes better than those who did not have that knowledge (table 2).

This study showed that knowledge about hypogly- caemia in patients with diabetes was poor, a result similar to previous studies done in Sri Lanka $(4,5)$. The study also showed that better knowledge of hypoglycaemic symptoms would help patients to recognise episodes of hypoglycaemia early, enabling them to take remedial action before going into hypoglycaemic coma. Early recognition of hypoglycaemic episodes would help them to identify and correct the predisposing factors, preventing occurrence of further attacks.

Table 1. Knowledge about symptoms, prevention and treatment of hypoglycaemia in relation to source of information

$\begin{array}{lccc} & \begin{array}{c}\text { Information } \\ \text { received from } \\ \text { a doctor } \\ (N=87)\end{array} & \begin{array}{c}\text { Information } \\ \text { received from } \\ \text { other sources } \\ (N=53)\end{array} & P \text { value } \\ \text { Knowledge of } & 30(34.5 \%) & 12(22.6 \%) & 0.138 \\ \text { Symptoms } & 26(29.9 \%) & 10(18.9 \%) & 0.148 \\ \text { Prevention } & 73(83.9 \%) & 44(83.6 \%) & 0.890 \\ \text { Treatment } & & & \end{array}$

Table 2. Identification and occurrence of hypoglycaemic episodes in relation to knowledge of hypoglycaemic symptoms

Knowledge of

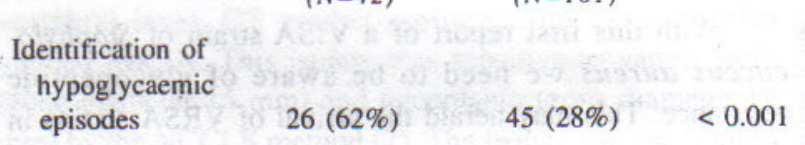

\section{Occurrence of} hypoglycaemic episodes

$33(79 \%)$

$84(52 \%)$

0.002

\section{References}

1. Bell JI, Hockaday TDR. Diabetes mellitus. In: Weatherall DJ, Ledingham JGG Warrell DA. Oxford Textbook of Medicine. 3rd ed. V.2. Oxford: Oxford University Press, 1996: 1448-1504.

2. Fernando DJS. Symptomatic hypoglycaemia in elderly diabetic patients. Ceylon Medical Journal 1994; 39: 110-1.

3. Cryer PE, Polonsky KS. Glucose homeostasis and hypoglycaemia. Williams Textbook of Endocrinology. 9th ed. Philadelphia: W. B. Saunders company, 1999; 947-8.

4. Fernando DJS. Knowledge about diabetes and metabolic control in diabetic patients. Ceylon Medical Journal 1993; 38: 18-21.

5. Chang AAPT, De Abrew K, Fernando DJS. An audit of structure, process and outcome of care of the diabetic clinic, National Hospital of Sri Lanka. Ceylon Medical Journal 1997; 42: 133-6.

E S Wijewickrama, Demonstrator, U C L Hewage, Senior Lecturer, and D J S Fernando, Professor, Department of Medicine, Faculty of Medical Sciences, University of Sri Jayawardenepura, Nugegoda. 